Effects of chemical st oi chi ometry of channel regi on on bi as i nst abi I ity i $\mathrm{n} \mathrm{ZnO} \mathrm{thi} \mathrm{n}$ - fil m transi st or $s$

\begin{tabular}{|l|l|}
\hline 著者 & $\begin{array}{l}\text { Kanada Yudai, Fuj i t a Shi zuo, Ki mur a Mit sumi , } \\
\text { H ramat su Takahi ro, Nat suda Toki yoshi, Fur ut a } \\
\text { Nanor u, Hi r ao Takashi }\end{array}$ \\
\hline $\begin{array}{l}\text { j our nal or } \\
\text { publ i cat i on ti t l e }\end{array}$ & Apl i ed Physi cs Let ter s \\
\hline vol une & 98 \\
\hline nunber & 10 \\
\hline page r ange & $103512-1-103512-3$ \\
\hline year & 2011- 03-10 \\
\hline URL & ht t p: //hdl . handl e. net /10173/953 \\
\hline
\end{tabular}




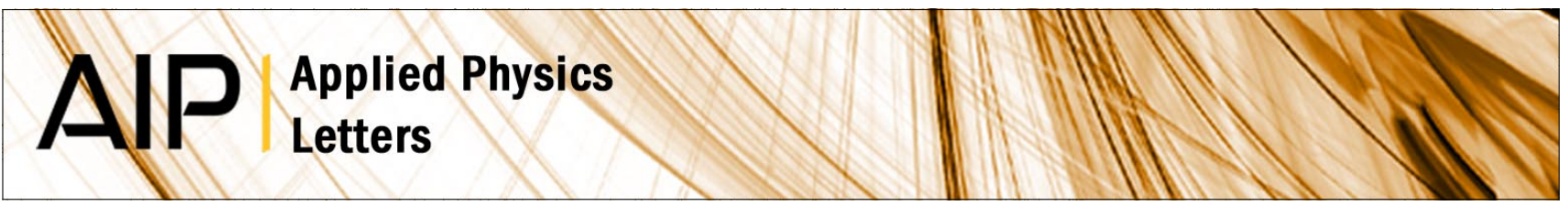

\section{Effects of chemical stoichiometry of channel region on bias instability in ZnO thin-film transistors}

Yudai Kamada, Shizuo Fujita, Mutsumi Kimura, Takahiro Hiramatsu, Tokiyoshi Matsuda et al.

Citation: Appl. Phys. Lett. 98, 103512 (2011); doi: 10.1063/1.3557066

View online: http://dx.doi.org/10.1063/1.3557066

View Table of Contents: http://apl.aip.org/resource/1/APPLAB/v98/i10

Published by the American Institute of Physics.

\section{Related Articles}

Demonstration and characterization of an ambipolar high mobility transistor in an undoped GaAs/AIGaAs quantum well

Appl. Phys. Lett. 102, 082105 (2013)

Investigation of the charge transport mechanism and subgap density of states in p-type Cu2O thin-film transistors Appl. Phys. Lett. 102, 082103 (2013)

Negative gate-bias temperature stability of $\mathrm{N}$-doped InGaZnO active-layer thin-film transistors Appl. Phys. Lett. 102, 083505 (2013)

A pH sensor with a double-gate silicon nanowire field-effect transistor

Appl. Phys. Lett. 102, 083701 (2013)

Extrinsic and intrinsic photoresponse in monodisperse carbon nanotube thin film transistors

Appl. Phys. Lett. 102, 083104 (2013)

\section{Additional information on Appl. Phys. Lett.}

Journal Homepage: http://apl.aip.org/

Journal Information: http://apl.aip.org/about/about_the_journal

Top downloads: http://apl.aip.org/features/most_downloaded

Information for Authors: http://apl.aip.org/authors

\section{ADVERTISEMENT}

\section{AIP Applied Physics Letters}

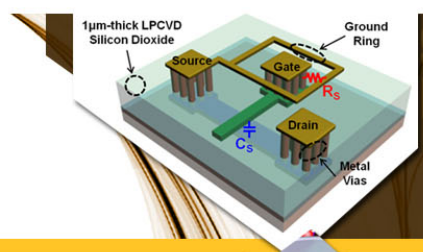

\section{SURFACES AND} INTERFACES

Focusing on physical, chemical, biological structural, optical, magnetic and electrical properties of surfaces and interfaces, and more..

\section{EXPLORE WHAT'S NEW IN APL}

SUBMIT YOUR PAPER NOW!
ENERCY CONVERSION AND STORACE

Focusing on all aspects of static and dynamic energy conversion, energy storage, photovoltaics, solar fueis, batteries, capacitors, thermoelectrics, 


\title{
Effects of chemical stoichiometry of channel region on bias instability in $\mathrm{ZnO}$ thin-film transistors
}

\author{
Yudai Kamada, ${ }^{1,2, a)}$ Shizuo Fujita, ${ }^{1}$ Mutsumi Kimura, ${ }^{3,4,5}$ Takahiro Hiramatsu, ${ }^{6}$ \\ Tokiyoshi Matsuda, ${ }^{6}$ Mamoru Furuta, ${ }^{6}$ and Takashi Hirao ${ }^{6}$ \\ ${ }^{1}$ Department of Electronic Science and Engineering, Kyoto University, Nishikyo-Ku, Kyoto 615-8520, Japan \\ ${ }^{2}$ Photonics and Electronics Science and Engineering Center, Kyoto University, Nishikyo-Ku, \\ Kyoto 615-8520, Japan \\ ${ }^{3}$ Department of Electronics and Informatics, Ryukoku University, Seta, Otsu 520-2194, Japan \\ ${ }^{4}$ Research Center for Science and Technology, Ryukoku University, Seta, Otsu 520-2194, Japan \\ ${ }^{5}$ Innovative Materials and Processing Research Center, Ryukoku University, Seta, Outsu 520-2194, Japan \\ ${ }^{6}$ Research Institute for Nanodevices, Kochi University of Technology, Kami, Kochi 782-8502, Japan
}

(Received 13 December 2010; accepted 1 February 2011; published online 10 March 2011)

\begin{abstract}
We investigated effects of chemical stoichiometry of $\mathrm{ZnO}$ channel, controlled by oxygen partial pressure during deposition, on bias instability for $\mathrm{ZnO}$ thin-film transistors. Parallel threshold voltage shifts were mainly enhanced under gate bias stresses due to charge trapping when O-rich $\mathrm{ZnO}$ was used for channel layer. On the contrary, negative threshold voltage shifts were observed under both gate and drain bias stresses when $\mathrm{Zn}$-rich $\mathrm{ZnO}$ was used for channel layer. This degradation was enhanced regardless of the bias polarity and the direction, attributing to electrically activated trap generations. () 2011 American Institute of Physics. [doi:10.1063/1.3557066]
\end{abstract}

Recently, technological progresses on oxide-based thinfilm transistors (TFTs) are increasingly demanded by rapid evolution of large area electronics such as active-matrix flat panel displays and organic-light emitting diode displays. ${ }^{1-3}$ Oxide-based TFTs have superior advantages because of their high field-effect mobility, ${ }^{4}$ excellent uniformity, lowprocessing temperature, ${ }^{5}$ and transparency in the visible light. ${ }^{6}$ Film properties of oxide materials are drastically influenced by deposition methods and conditions. Especially, it is well known that oxygen pressure during oxide film deposition influences the formation of subgap density of states which play an important role in the TFT performance. ${ }^{7}$ However, there is still much unknown physics of the density of states in oxide-based TFTs such as its effect on the device characteristics and bias stability, the defect physics, and so on. We have reported that a $\mathrm{ZnO}$ deposited under a low oxygen partial pressure included lots of donor-like traps near the conduction energy and these traps deteriorated the subthreshold characteristics of ZnO TFTs. ${ }^{8}$

In this paper, we report the effects of chemical stoichiometry in $\mathrm{ZnO}$ channel on bias stability of ZnO TFTs. The chemical stoichiometry was controlled by changing the oxygen partial pressure during deposition of $\mathrm{ZnO}$ via radio frequency (rf) magnetron sputtering that is commonly-used in large area electronics manufacturing.

Bottom-gate $\mathrm{ZnO}$ TFTs were fabricated on alkali-free glass substrates. First, a $50 \mathrm{~nm}$ thick chromium gate electrode was formed via dc magnetron sputtering and a gate insulator consisted of $\mathrm{SiO}_{x} / \mathrm{SiN}_{x}$ stacked layer was deposited at $350{ }^{\circ} \mathrm{C}$ via conventional plasma-enhanced chemical vapor deposition. Then, a $40 \mathrm{~nm}$ thick $\mathrm{ZnO}$ active layer was deposited at $150{ }^{\circ} \mathrm{C}$ via rf magnetron sputtering. An oxygen partial pressure $\mathrm{O}_{2} /\left(\mathrm{O}_{2}+\mathrm{Ar}\right)$ during the $\mathrm{ZnO}$ deposition was set at 0.33 or $0.75 \mathrm{~Pa}$, whose value was optimized to obtain

\footnotetext{
a) Author to whom correspondence should be addressed. Electronic mail: kamada@icc.kyoto-u.ac.jp.
}

$\mathrm{Zn}$-rich $\mathrm{ZnO}$ or O-rich $\mathrm{ZnO}$, in order to compare the effects of chemical stoichiometry in the $\mathrm{ZnO}$ layers. After the $\mathrm{ZnO}$ deposition, the $\mathrm{ZnO}$ was covered with a $\mathrm{SiN}_{x}$ layer deposited at $250{ }^{\circ} \mathrm{C}$ and separated to an individual channel area of a TFT via photolithography and dry etching. A $200 \mathrm{~nm}$ thick $\mathrm{SiN}_{x}$ film was subsequently deposited onto the patterned $\mathrm{SiN}_{x} / \mathrm{ZnO}$ bilayers, forming contact holes for source and drain contacts. Then, a $50 \mathrm{~nm}$ thick ITO was deposited and patterned for source and drain electrodes. Finally, a $200 \mathrm{~nm}$ thick $\mathrm{SiN}_{x}$ film was deposited for a passivation layer. The channel width and length of the fabricated TFTs were $50 \mu \mathrm{m}$ and $20 \mu \mathrm{m}$, respectively. The ZnO TFTs with $\mathrm{ZnO}$ channel deposited under the oxygen partial pressure of 0.33 $\mathrm{Pa}$ or $0.75 \mathrm{~Pa}$ were thermally annealed at $360{ }^{\circ} \mathrm{C}$ or $375{ }^{\circ} \mathrm{C}$ for $3 \mathrm{~h}$ in nitrogen atmosphere, respectively, ensuring that it was easy to make comparison for almost the same on-state characteristics.

Figures 1(a) and 1(b) show the thermal desorption spectroscopy (TDS) spectra of zinc and oxygen, respectively, obtained from the $\mathrm{ZnO}$ films deposited under the oxygen partial pressure of 0.33 and $0.75 \mathrm{~Pa}$. It is found that the desorption characteristics are strongly influenced by the oxygen partial pressure during the deposition. $\mathrm{Zn}$ is mainly desorbed from the $\mathrm{ZnO}$ film deposited under the lower oxygen partial pressure (Zn-rich mode). On the contrary, the $\mathrm{ZnO}$ films deposited under the higher oxygen partial pressure (O-rich mode) show only oxygen desorption.

Figure 2(a) shows the transfer characteristics of the $\mathrm{ZnO}$ TFTs with the inset of the TFT structure. The transfer characteristics of the TFTs with $\mathrm{ZnO}$ deposited under oxygen partial pressure of 0.17 (Zn-rich mode) and $0.50 \mathrm{~Pa}$ (O-rich mode) are simultaneously shown for comparison. It clearly shows a dependence of the subthreshold characteristics on the oxygen partial pressure during the $\mathrm{ZnO}$ deposition. Although the on-state currents for all ZnO TFTs are almost the same, the hump characteristic is only observed in the subthreshold region of the $\mathrm{Zn}$-rich $\mathrm{ZnO}$ TFT. This hump is at- 


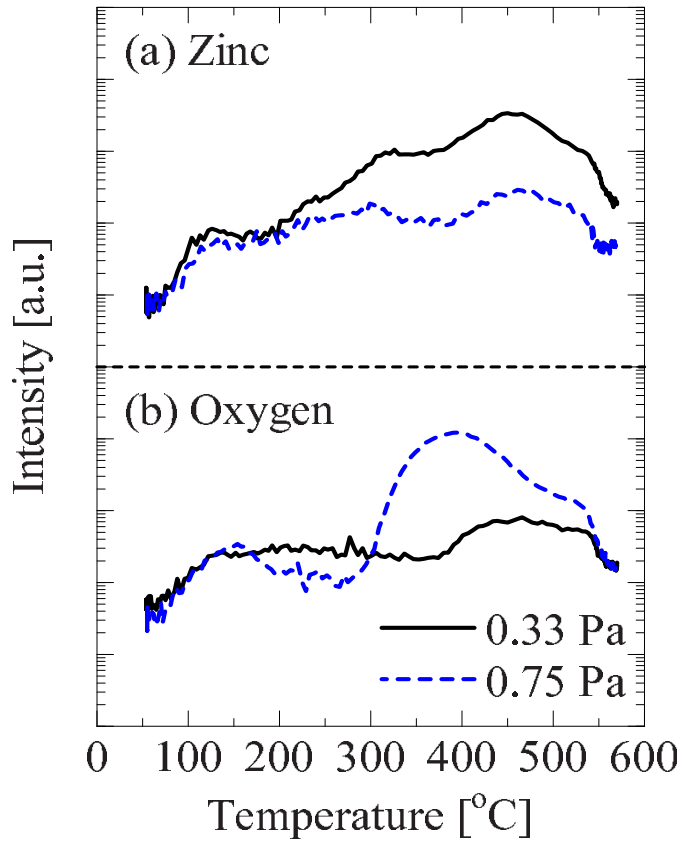

FIG. 1. (Color online) TDS spectra of (a) zinc and (b) oxygen from the $\mathrm{ZnO}$ films deposited under oxygen partial pressures of 0.33 and $0.75 \mathrm{~Pa}$.

tributed to the increase in donor-like traps near the conduction band edge $\left(E_{\mathrm{c}}\right)^{8}$

Figure 2(b) shows the trap densities in the $\mathrm{ZnO}$ channel layers as a functions of the energy $(E)$ from the $E_{\mathrm{c}}$ extracted from low-frequency capacitance-voltage measurements. The details of the characterization methods were reported in a previous paper. ${ }^{9}$ The TFT with $\mathrm{Zn}$-rich $\mathrm{ZnO}$ includes a larger trap density near the conduction band of $\mathrm{ZnO}$. As a result, the subthreshold characteristic is deteriorated as the appear-

(a)

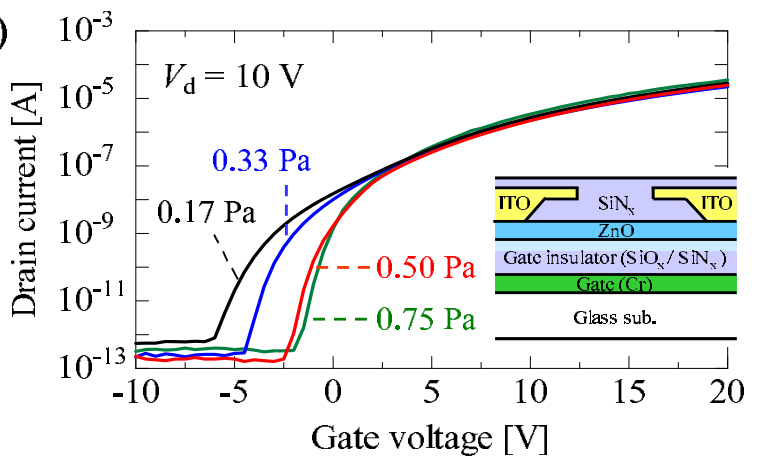

(b)

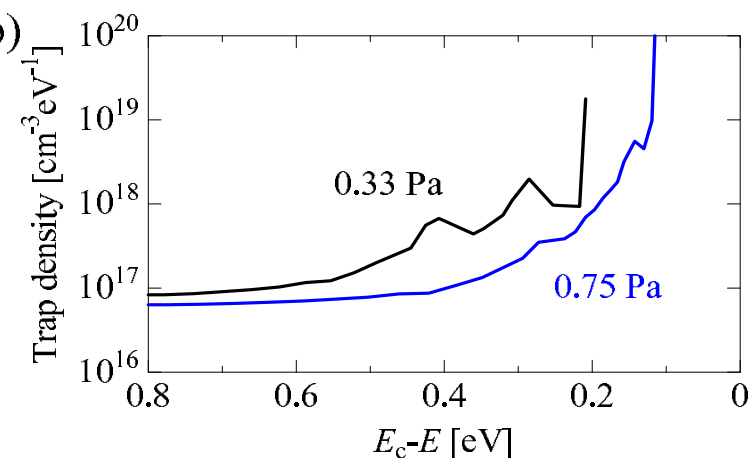

FIG. 2. (Color online) (a) Transfer characteristics of the ZnO TFTs when the $\mathrm{ZnO}$ channels were deposited under oxygen partial pressure from 0.17 to $0.75 \mathrm{~Pa}$. The inset is device structure, and (b) trap densities in the $\mathrm{ZnO}$ channel layers as a functions of the energy from the conduction band. (a)

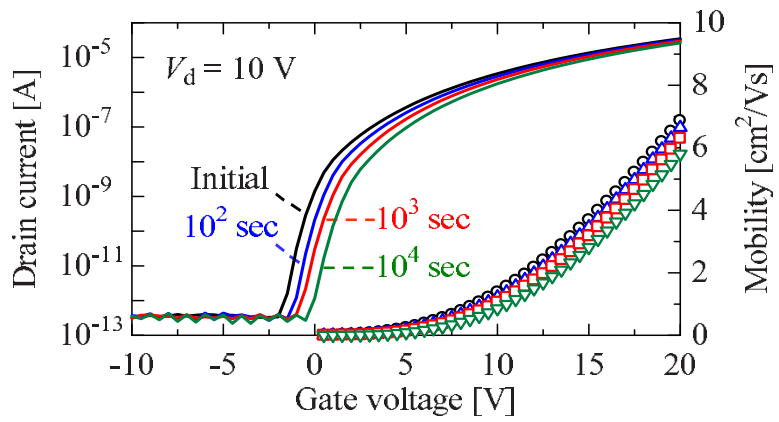

(b)

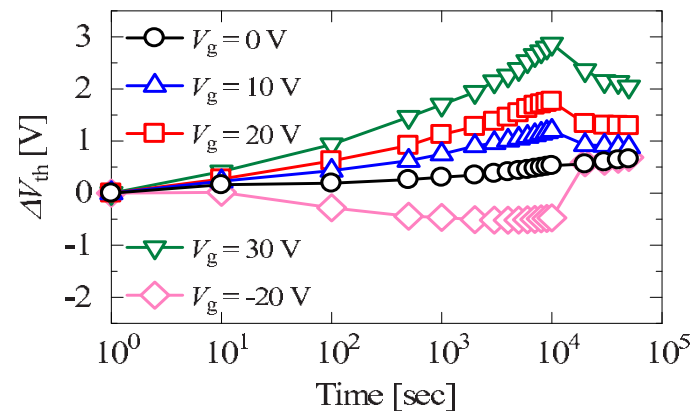

(c)

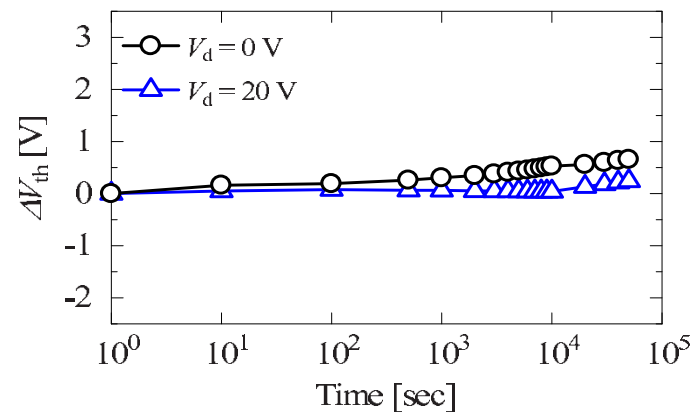

FIG. 3. (Color online) Bias instability results for the TFT with O-rich $\mathrm{ZnO}$. (a) The change in transfer characteristics under a gate bias stress of $20 \mathrm{~V}$ and a drain bias stress of $0 \mathrm{~V}$. The change in linear mobility is also indicated with $\bigcirc$ : initial, $\triangle: 10^{2} \mathrm{~s}, \square: 10^{3} \mathrm{~s}$, and $\nabla: 10^{4} \mathrm{~s}$, respectively, (b) the variation in $V_{\text {th }}$ from the initial value under various gate bias stresses without drain bias stress, and (c) the variation in $V_{\text {th }}$ from the initial value under various drain bias stresses without gate bias stress.

ance of undesirable hump characteristic because the traps near the conduction band cause degradation of potential modulation against the gate voltage sweep. The origin of the larger number of traps in $\mathrm{Zn}$-rich $\mathrm{ZnO}$, shown in Fig. 1(b), is attributed to the effects of excess $\mathrm{Zn} .{ }^{10-12}$

Stress-tests under various bias conditions were carried out for the TFTs with O-rich or $\mathrm{Zn}$-rich $\mathrm{ZnO}$. The mechanism of bias instability was elucidated by measuring the transfer characteristics when a gate bias stress between -20 and $30 \mathrm{~V}$ or a drain bias stress between 0 and $20 \mathrm{~V}$ was applied. The stress duration was $10^{4} \mathrm{~s}$ and the recovery properties after the stress were also measured till $5 \times 10^{4} \mathrm{~s}$. Figure 3 shows the experimental results for the TFT with O-rich $\mathrm{ZnO}$ in which (a) the change in transfer characteristics under a gate bias stress of $20 \mathrm{~V}$ and a drain bias stress of $0 \mathrm{~V}$, (b) the variation in threshold voltage $\left(V_{\mathrm{th}}\right)$ from the initial value under various gate bias stresses without drain bias stress, and (c) the variation in $V_{\text {th }}$ from the initial value under various drain bias stresses without gate bias stress. Here, we defined $V_{\text {th }}$ as a gate voltage when a drain current of $1 \mathrm{nA}$ could flow at a drain voltage of $10 \mathrm{~V}$. The transfer characteristics positively shifted as the stress time is increased under positive gate bias and the gate-voltage- 
(a)

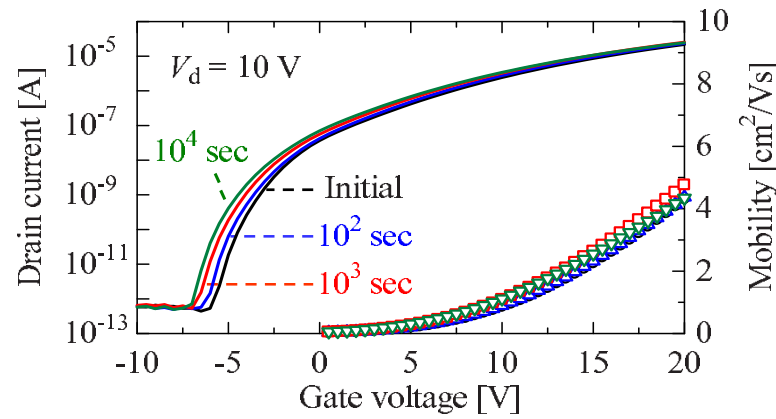

(b)

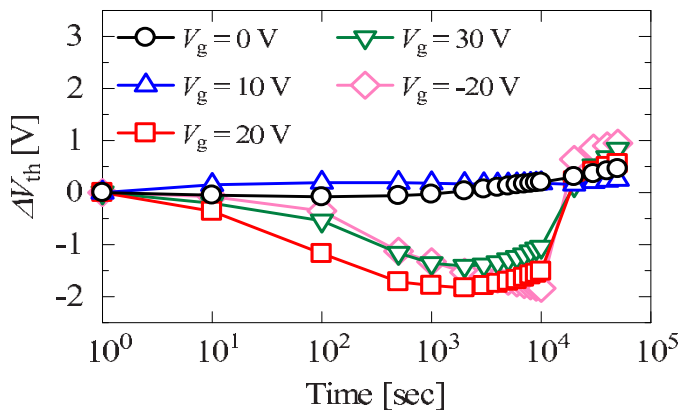

(c)

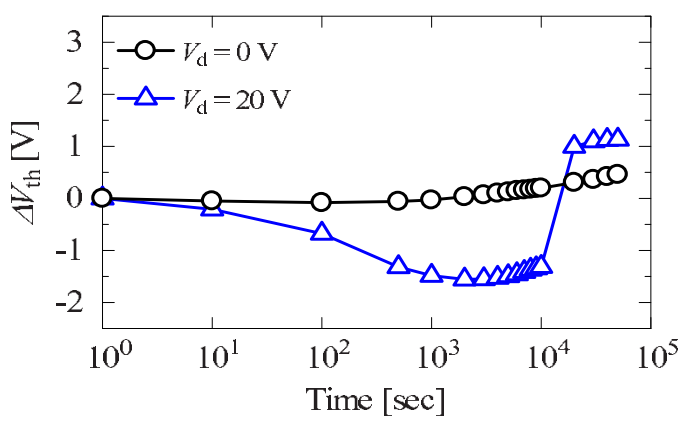

FIG. 4. (Color online) Bias instability results for the TFT with $\mathrm{Zn}$-rich $\mathrm{ZnO}$. (a) The change in transfer characteristics under a gate bias stress of $20 \mathrm{~V}$ and a drain bias stress of $0 \mathrm{~V}$. The change in linear mobility is also indicated with $\bigcirc$ : initial, $\triangle: 10^{2} \mathrm{~s}, \square: 10^{3} \mathrm{~s}$, and $\nabla: 10^{4} \mathrm{~s}$, respectively, (b) the variation in $V_{\text {th }}$ from the initial value under various gate bias stresses without drain bias stress, and (c) the variation in $V_{\text {th }}$ from the initial value under various drain bias stresses without gate bias stress.

dependent linear mobility was changed. This phenomenon is similar to the transfer characteristics shift as shown in Fig. 3(a). To the contrary, it is found that the transfer characteristics are negatively shifted under a negative gate bias stress as shown in Fig. 3(b). A linear relationship between the $V_{\text {th }}$ shift and the logarithmic stress time without significant changes in the subthreshold swing and field-effect mobility after the stress suggests that the bias instability may be attributed to the negative charge trapping in the gate insulator and/or the channel/dielectric interface as reported in the literatures. ${ }^{13-15}$ Therefore, the $V_{\text {th }}$ shift is nearly independent of the drain bias stresses as shown in Fig. 3(c) since the stress along the lateral direction induced by the drain bias do not enhance charge trapping into the gate insulator. The slow recovery time extending to more than $10^{4} \mathrm{~s}$ can be explained by the slow detrapping properties from the gate insulator. On the contrary, quite different results are obtained for the TFTs with the $\mathrm{Zn}$-rich $\mathrm{ZnO}$ as shown in Fig. 4. The transfer characteristics are negatively shifted regardless of the polarities of the gate bias stresses as shown in Figs. 4(a) and 4(b).
Additionally, the drain bias stresses also enhance the negative $V_{\text {th }}$ shift. The negative shifts in the transfer characteristics are obviously due to a mechanism that is different from the charge trapping. The origin is thought to be that more inactivated $\mathrm{Zn}$-related defect states are present in the Zn-rich $\mathrm{ZnO}$ and these defects are electrically activated and/or new defects are generated by the bias stress. As a result, the $V_{\text {th }}$ is negatively shifted due to the enhancement in the hump characteristics. The negative $V_{\text {th }}$ shift enhanced by electrically active traps seems to appear dominantly though the charge trapping also occurred in the Zn-rich ZnO TFTs.

In conclusion, mechanisms of bias instability in the $\mathrm{ZnO}$ TFTs with Zn-rich or O-rich film compositions were investigated by changing the oxygen partial pressure during the $\mathrm{ZnO}$ deposition. Positive $V_{\text {th }}$ shift mainly occurred under positive gate bias for the TFTs with the $\mathrm{ZnO}$ channel layer deposited under O-rich conditions due to negative charge trapping. On the contrary, negative $V_{\text {th }}$ shift was enhanced for the TFTs with the $\mathrm{ZnO}$ channel layer deposited under $\mathrm{Zn}$-rich conditions due to electrically activated trap generations. These results suggest that slight excess chemical elements in a $\mathrm{ZnO}$ channel layer influence the main origin of bias instability. Therefore, precise control of chemical compositions in the $\mathrm{ZnO}$ channel layer is crucial for realizing high stability against bias stresses in oxide TFTs.

This work was supported by a Grant-in-Aid for Scientific Research from the Japan Society for the Promotion of Science (20-6841).

${ }^{1}$ J. Y. Kwon, K. S. Son, J. S. Jung, T. S. Kim, M. K. Ryu, K. B. Park, B. W. Yoo, J. W. Kim, Y. G. Lee, K. C. Park, S. Y. Lee, and J. M. Kim, IEEE Electron Device Lett. 29, 1309 (2008).

${ }^{2}$ H. N. Lee, J. Kyung, M. C. Sung, D. Y. Kim, S. K. Kang, S. J. Kim, C. N. Kim, H. G. Kim, and S. T. Kim, J. Soc. Inf. Disp. 16, 265 (2008).

${ }^{3}$ H. Ohara, T. Sasaki, K. Noda, S. Ito, M. Sasaki, Y. Endo, S. Yoshitomi, J. Sakata, T. Serikawa, and S. Yamazaki, Jpn. J. Appl. Phys. 49, 03CD02 (2010).

${ }^{4}$ H. Yabuta, M. Sano, K. Abe, T. Aiba, T. Den, H. Kumomi, K. Nomura, T. Kamiya, and H. Hosono, Appl. Phys. Lett. 89, 112123 (2006).

${ }^{5}$ K. Nomura, H. Ohta, A. Takagi, T. Kamiya, M. Hirano, and H. Hosono, Nature (London) 432, 488 (2004).

${ }^{6}$ J. Nishii, F. M. Hossain, S. Takagi, T. Tita, K. Saikusa, Y. Ohmaki, I. Ohkubo, S. Kishimoto, A. Ohtomo, T. Fukumura, F. Matsukura, Y. Ohno, H. Koinuma, H. Ohno, and M. Kawasaki, Jpn. J. Appl. Phys., Part 2 42, L347 (2003)

${ }^{7}$ H.-H. Hsieh, T. Kamiya, K. Nomura, H. Hosono, and C.-C. Wu, Appl. Phys. Lett. 92, 133503 (2008)

${ }^{8}$ M. Furuta, Y. Kamada, M. Kimura, T. Hiramatsu, T. Matsuda, T. Furuta, C. Li, S. Fujita, and T. Hirao, IEEE Electron Device Lett. 31, 1257 (2010).

${ }^{9}$ M. Kimura, T. Nakanishi, K. Nomura, T. Kamiya, and H. Hosono, Appl. Phys. Lett. 92, 133512 (2008).

${ }^{10}$ F. Oba, S. R. Nishitani, S. Isotani, H. Adachi, and I. Tanaka, J. Appl. Phys. 90, 824 (2001).

${ }^{11}$ S. B. Zhang, S.-H. Wei, and A. Zunger, Phys. Rev. B 63, 075205 (2001)

${ }^{12}$ M. Willander, O. Nur, J. R. Sadaf, M. I. Qadir, S. Zaman, A. Zainelabdin, N. Bano, and I. Hussain, Materials 3, 2643 (2010).

${ }^{13}$ C.-T. Tsai, T.-C. Chang, S.-C. Chen, I. Lo, S.-W. Tsao, M.-C. Hung, J.-J. Chang, C.-Y. Wu, and C.-Y. Huang, Appl. Phys. Lett. 96, 242105 (2010).

${ }^{14}$ M. Furuta, Y. Kamada, T. Hiramatsu, C. Li, S. Fujita, and T. Hirao, "Positive Bias Instability of Bottom-Gate Zinc Oxide Thin-Film Transistors (ZnO TFTs) with a $\mathrm{SiO}_{x} / \mathrm{SiN}_{x}$ Stacked Gate Insulator," Jpn. J. Appl. Phys. (to be published).

${ }^{15}$ J. Lee, J.-S. Park, Y. S. Pyo, D. B. Lee, E. H. Kim, D. Stryakhilev, T. W. Kim, D. U. Jin, and Y.-G. Mo, Appl. Phys. Lett. 95, 123502 (2009). 